\title{
INVESTIGACIÓN SALVAJE Y PROSA RITUAL EN LA SOCIEDAD SERIAL: PASAJES ENTRE DERECHO Y LITERATURA
}

\author{
PESQUISA SELVAGEM E PROSA RITUAL NA SOCIEDADE SERIADA: PASSAGENS \\ ENTRE DIREITO E LITERATURA
}

\section{WILD RESEARCH AND PROSA RITUAL IN THE SERIATED SOCIETY: PASSAGES BETWEEN LAW AND LITERATURE}

\author{
AGUIRRE, Gonzalo S. \\ zonawong@gmail.com \\ Universidad de Buenos Aires \\ https://orcid.org/0000-0003-2324-0237
}

RESUMEN Consumada la algoritmización que da lugar al paso definitivo de las sociedades disciplinarias a las sociedades de control, nos encontramos transitando senderos postcontroladores de carácter serial. Quisiéramos atender a la manifestación de tal tránsito en la producción serial de papers académicos, en el contexto de la pérdida de fuerza conductora y de gobierno de plataformas expresivas como Derecho y Literatura, y de la aparición de nuevas plataformas expresivas de gobierno como Netflix o Spotify. Procuramos asimismo, partiendo de la noción de "prosa del pensamiento" de Miguel Morey, dejar planteadas alternativas de escritura y gobierno a las de la sociedad serial.

Palabras claves: Derecho. Investigación. Literatura. Paper. Prosa del pensamiento. Sociedad Serial

RESUMO Concluída a algoritmização que dá origem à passagem definitiva das sociedades disciplinares para as sociedades de controle, estamos transitando caminhos pós-controle de natureza serial. Gostaríamos de ver a manifestação de tal trânsito na produção seriada de trabalhos acadêmicos, no contexto da perda da força expressiva e de governança de plataformas como o Direito e a Literatura, e o surgimento de novas plataformas governamentais expressivas como Netflix ou Spotify. Procuramos também, oferecer alternativas de escrita e governo às da sociedade serial, começando desde la noção de "prosa de pensamento" de Miguel Morey.

Palavras-chaves: Direito. Literatura. Paper. Pesquisa. Prosa de pensamento. Sociedade seriada.

ABSTRACT Once has been completed the algorithmization that gives rise to the definitive passage of the disciplinary societies to the control societies, we are transiting post-control paths of a serial nature. We would like to see the manifestation of such a transit in the serial production of academic papers, in the context of the loss of expressive force and governance of platforms such as Law and Literature, and the emergence of new expressive government platforms such as Netflix or Spotify. We also try to offer alternatives for writing and government to those of the serial society, starting from the notion of "prose of thought" by Miguel Morey.

Key Words: Law. Literature. Paper. Prose of thought. Research. Serial Society. 


\begin{abstract}
"Pero nosotros no pensamos en palabras. Pensamos a veces en palabras. Las palabras son archipiélagos fluctuantes y esporádicos. La mente es el mar. Reconocer en la mente este mar parece algo prohibido, que las ortodoxias vigentes, en sus diversas versiones, científicas o sólo commonsensical, evitan casi por instinto.

Pero radica aquí, precisamente, la bifurcación esencial. Aquí es donde se decide en que dirección se moverá el conocimiento." (Calasso, 2002, p. 115)

"Desde que fueron excluidos los juegos y el comercio de los sofistas, desde que se ha amordazado, con mayor o menor seguridad, sus paradojas, parece que el pensamiento occidental haya velado por que en el discurso haya el menor espacio posible entre el pensamiento y el habla." (Foucault, 2008, p. 47)
\end{abstract}

\title{
1 NO TE CONVIERTAS EN LO QUE ERES: DE LA INVESTIGACIÓN SALVAJE
}

Quisiéramos proponer una investigación digna de "detectives salvajes".

Quisiéramos recordar que toda investigación auténtica es salvaje, no normalizada.

La investigación domesticada, academizada ha de ser una zona de descanso, de recuperación de la fuerza investigadora. Esta es salvaje, indómita, aún cuando conlleve necesariamente rituales de expresión. La normalización académica conlleva una separación de los investigadores de la condición ritual de su faena, lo que suscita una separación de su propia fuerza indómita de procedencia.

El sentido de la estandarización de la escritura académica sólo puede ser el de brindar refugio a los investigadores salvajes. Un área de solaz, de esparcimiento previa y posterior a "los sinsabores del verdadero policía." Perder esto de vista es condenar la expresión ritual, cuyo sentido radica en reproducir la fuerza expresiva que custodia, a convertirse en una mera sucesión arbitraria de instrucciones sin otro sentido que el de reproducirse ella misma.

Por eso la escritura académica, para sobrevivir, ha de arriesgarse por zonas no exploradas; riesgo que, por otro lado, tendría su propia tradición: como la retórica especulativa que rastrea Pascal Quignard - - -

- - - aquí, según los usos formales en vigencia, debiera alguna referencia bilbiográfica sobre el autor mencionado. Quedará, sin embargo, en una suerte de suspenso metodológico a los efectos de asumir, dentro de lo formalmente posible, el riesgo mencionado. Quizás valga aquí la pena una disquisición al límite de las formas cuya lectura puede saltearse:

Si bien este artículo intenta, entre otras cosas, intervenir en el régimen estandarizado de la cita, lo hace promoviendo su valor "amoroso" sin desconocer, a la vez, su valor 
académico procedimental. En nuestras investigaciones junto a Christian Kessel, enmarcadas en lo que llamamos Estética del Derecho, intentamos aquilatar este último valor cuya procedencia, primeramente, ha de rastrearse en el nacimiento del gobierno de la Oficina (o Buro-cracia), en combinación con el Derecho procedimental-formal propio de los Estados de Derecho. Al respecto podría decirse que la lógica formal con arreglo a fines que destacara Max Weber a la hora de definir un tipo de gobierno cuya legitimidad es racional resulta, al día de hoy, una lógica formal sin arreglo a fin alguno más que el de su propia consecución. Los fines utilitarios que, como recuerda Sara Lagi, quedaban según Hans Kelsen en manos del Parlamento como órgano de la Sociedad (y no del Estado, por ser este esencialmente formal-normativo), habrían dejado de ser producidos o, al menos, habrían dejado de ser orientadores predominantes de los procedimientos formales. En ese marco podría atenderse a la expresión "Giro Lingüístico" como un intento de dar cuenta del paso de la racionalidad formal con arreglo a fines, a una tal racionalidad pero sin arreglo a ningún otro fin que el del propio funcionamiento de esta racionalidad formal. Este funcionamiento resulta ciertamente lingüístico, si se asume a la Lengua como un sistema gramatical con capacidad performativa ilimitadamente formalizable.

Sumariamente, podría indicarse que el algoritmo de búsqueda de Google funciona a partir del mismo principio de indexación de los textos académicos: cuanto más citado un texto/autor, tanto más importante es este texto/autor y, a su vez, tanto más importante es una cita si se trata de una cita hecha por un texto/autor que detenta asimismo un alto nivel de citaciones. Con esto se quiere indicar que ya a nivel de las práctica sociales más cotidianas nos encontramos inmersos en un régimen constante de la cita que se autoreproduce. Ahora bien, justamente en este punto se torna imprescindible rastrear la procedencia de este régimen que, notablemente, resulta ser académico y, a su vez, rastrear esta práctica académica en el paso del régimen de trasmisión de conocimiento conocido como Bildung/Gestaltung (formación/design) al de la Big Science, paso articulado justamente sobre el campo de batalla de la Segunda Guerra Mundial; más específicamente, sobre la carrera científica para la consecución de la "bomba atómica". Esta tarea requeriría aunque más no sea una mínima pausa en el "régimen de la cita". Es por ello que este artículo, sin perder de vista ni la "utilidad" de las citas, ni su sentido performativo, intenta hacerlas pasar de otro modo: no como mera constancia de conocimiento o de autoreferencialidad, si no también como instancia de concertación amorosa, tal y como queda 
resonando en la expresión "concertar una cita". De allí que a lo largo de todo el texto, y especialmente en las Referencias finales, Lectora y Lector podrán dar con todo aquello que precisen para satisfacer su eventual curiosidad amorosa, y "concertar una cita" con la referencias que les hubiere llamado la atención o con el que hubieren entrado en afinidad electiva (Wahlverwantschaften). De la misma manera, entendemos que el sistema formal de constatación de conocimiento o de regulaciones performativas quedará satisfecho aún cuando a primera vista algunos años de edición queden elididos, justamente para hacer la pausa ya mencionada y favorecer, si se puede decir así, un "amor a primera vista" entre Lector/a y referencia - - -

- - - [retomando] A la tradición de la retórica especulativa se sumaría también una suerte de tradición porvenir (tributaria de la "filología del futuro" implicada en el gesto expresivo nietzscheano) que ha postulado Miguel Morey: la prosa del pensamiento. Esta podría resultar una vía para recuperar el sentido de la orientación en el mundo que ha quedado luego de la disolución de la prosa del mundo: el mundo de la prosa de la Historia.

Si, como planteara el mismo Morey en su prólogo de 1997 al libro de Deleuze Lógica del sentido, el pensar es una forma de patología superior, podría decirse que el pensamiento tiene algo de investigación salvaje, pathica. Precisa por ello procurarse los modos de expresión que le correspondan, siempre a riesgo de no lograr la consistencia que precisa para conducir ese afecto llamado pensamiento que, a fin de cuentas, resulta ser, rodeo más o menos, el asunto constante de toda investigación, incluso la más científica y orientada a políticas públicas, incluso si se trata de descubrir un modo de combatir la caspa o de evitar la transpiración corporal, o de lograr un tejido impermeable de uso cotidiano. De allí que nos gustaría postular a la escritura académica estandarizada como un intento de conjurar todos esos intentos de expresión fallidos; y de hacerlo sin anular todo intento ni, mucho menos, todo logro de consistencia expresiva no estandarizada en aras de una supuesta coherencia investigadora predeterminada. La Academia podría postularse como un espacio de encuentro de investigadores, como un refugio de alta montaña, como un espacio para compartir la experiencia de recuperación de la fuerza investigadora. De otro modo se transforma en lo que tendencialmente ya es: una Oficina de Administración del Discurso y de su Orden: l'ordre du discours le llamaba Foucault: el orden discurso custodiado por la Orden del Discurso. Un espacio lóguico devenido espacio de dominio y de dominación que, tendencialmente, habrá de obligar a los investigadores salvajes de todo tipo a refugiarse en lo que Maurice Blanchot llamara espacio literario. 
Experiencias de escritura como las llevadas adelante por Friedrich Nietzsche, o Walter Benjamin, o Gilles Deleuze-Félix Guattari, o Georges Bataille, o Gilbert Simondon o Macedonio Fernández, y tantas otras que hoy pueden salirnos al encuentro ante la larga crisis de la escritura disciplinar, corren el riesgo de diluirse en el torbellino digital de papers monográficos que nada arriesgan y que, por lo tanto, nada pueden perder. Como si aquellas experiencias de escritura que durante mucho tiempo resultaron refractarias a la Ciencia y a la Academia, se hubiesen ido transformando lentamente en su reserva o fuente de sentido, de la que ahora obtienen la energía para seguir produciendo lo mismo: una escritura sin experiencia de sí, una investigación separada de su salvajismo y de su correspondiente ritualización.

A esta altura del siglo XXI los papers o informes que resultan de cualquier investigación pueden ser producidos por un mínimo software, a su vez escrito por un programador que, tendencialmente, puede ser reemplazado por otro mínimo software. El affaire Sokal no mostraba que las "ciencias humanas" no tienen parámetros adecuados para validar sus resultados expresivos; más bien al contrario mostraba y muestra que las antaño conocidas como "ciencias exactas" son las que dominan la lógica de la producción científica de papers en serie: su modo expresivo dominante apoyado en "resultados concretos", esto es en políticas más o menos públicas de gobierno, corresponde necesariamente con sus esquemas de producción de conocimiento. El affaire Sokal así, descubrió el espejo de toda producción científica, y esta se dejó reflejar en él con toda la fuerza narcisística de la que fue capaz: per oculos perit ipse suos. Sokal demostró rigurosamente que todas sus anteriores publicaciones científicas, equivalentes a las de cualquier otro investigador, eran una impostura. Así, al no comprender su propia broma, al no detectar que la imagen reflejada en ella era su propia imagen, pereció por su propia escritura.

\section{PLATAFORMAS DE EXPRESIÓN: SAPERE AUDE}

Comprendemos las necesidades coyunturales de la producción de saber. Las aceptamos y favorecemos. Pero no por ello hemos de renunciar a la fuente salvaje de toda investigación, ni al intento de dar lugar a una expresión precisa de los resultados que esta pueda suscitar.

Agotadas o abandonadas plataformas expresivas como "Filosofía","Escultura", "Poesía", "Pintura", "Literatura", "Cine", hemos de estar tras un nuevo modo expresivo que pueda dar cuenta de los excedentes (salvajes) de toda investigación expresada 
estandarizadamente. Netflix es una nueva plataforma para transmitir y generar contenidos audiovisuales, que lidia triunfantemente con la crisis de los modos estandarizados de transmisión a distancia inaugurada por la Guerra Fría y sus misiles intercontinentales. Spotify hace lo propio con la transmisión de contenidos auditivos anteriormente conocidos como "canciones". ¿Sabremos crear una nueva plataforma expresiva para los excedentes de la producción académica? ¿Plataformas como Lattes en Brasil o Sigeva en Argentina, o la Comunidad Europea de Conocimiento inaugurada por la Reforma de Bologna, podrán considerarse análogas a Netflix o Uber? Y principalmente, ¿contemplan estas plataformas el salvajismo investigativo del pensiero, o son nuevos modos de seguir separados de la ritualización de la expresión? ¿O no pueden ser otra cosa que eso? Una vez más la divisa ilustrada, la pregunta de la esfinge reformulada nos convoca: sapere aude (anímate a saber). Como planteara Michel Foucault en sus dos artículos cuasi-testamentarios de 1983 y 1984 titulados ambos “¿Qué es la llustración?”, cada vez que surge esa fórmula es que estamos ante una ontología del presente, ante una ontología de nosotros mismos. La cuestión parece radicar en alcanzar el gesto por el cual esa animación, ese animarse, no proceda de un artilugio retórico. Más bien a la inversa: que todo artilugio retórico resulte de esa animación, de aquello que en Grecia habrán llamado persuasión.

Operativamente, inmediatamente, a nuestros efectos, la cuestión podría plantearse así: ¿nos animaremos a escribir sin citar? ¿Podremos leer sin citas? Sería preciso generar un nuevo estatuto de confianza que prescinda del Autor, del Lector y de la prueba, de la cita como prueba. Un estatuto que no quede monopolizado por los procedimientos insulsos y auto-referenciales de Wikipedia, si no que también pueda dar lugar a una auténtica participación en aquello que se conoce, que se sabe: la cita considerada como "cita amorosa", como indicación de un lugar de encuentro entre lo que se conocía como Autor y lo que pervive como Lector. De otro modo es la "cita amorosa" la que queda contagiada por el régimen académico-jurídico de la cita como prueba: todo deviene Erwartung (Espera), como bien explica Barthes en Fragmentos de un discurso amoroso: si no viene, no me quiere; si no (me) cita, no (me) sabe; si no da referencias, es que no conoce, es que no se orienta.

De nuevo, no se trataría de oponerse a los estándares, si no más bien de comprenderlos, de atender a su procedencia. Sin esa comprensión toda tentativa de composición de nuevos modos expresivos se encontraría, desde el vamos, desorientada y sujeta a una inconsistencia tal que no sólo quedaría fuera del juego estandarizado, si no 
también fuera del juego salvaje. No se trataría entonces de anular las citas, si no más bien de transvalorarlas. Citar salvaje y ritualizadamente o, al menos, con noción y participación del régimen de citas estandarizado. Esa Participación no resulta algoritmizable, como tampoco lo es aquella Espera (Erwartung) que suscita como excedente el régimen burocrático-jurídico de la cita.

Ahora bien, el tránsito de esta experiencia conlleva ritmos geológicos. No se construye una nueva forma, ni se logra una adecuada composición expresiva de un día para otro por decisión voluntaria. Más bien hay un reconocer nuevas formas en el movimiento constante del magma expresivo. Al fin de cuentas, quizás resulte que lo que estemos buscando sea algo que ya hemos conseguido varias y contadas veces a lo largo del ínfimo instante que ocupa la historia del conocimiento humano.

\section{MUERTE DE LA ESCRITURA NOCTURNA: ACERCA DE LA ESCRITURA SERIAL}

En un bellísimo texto de 1966, de bellísimo título, Les mots et les choses, Michel Foucault dio cuenta de la muerte del Hombre. Cosas del mar y de las arenas. Ahora bien, la Literatura es una forma o plataforma expresiva que correspondía a la formación "hombre". Así también el Derecho Procesal moderno. La Literatura procesaba los excedentes dramáticos que insistían y persistían más allá del Proceso jurídico. Literatura y Derecho son dos formas suplementarias del Orden del Discurso. La primera, escritura murciélaga, batwriting, operaba a la sombra de la segunda: "La noche sienta doctrina", indica Miguel Morey; la palabra se despliega nocturnamente, por entre las claridades del Orden del Discurso.

Ante un título como Les mots et les choses (Las palabras y las cosas), nunca se hará suficiente hincapié en el desliz de sentido que circula entre la palabra "mot" y la palabra "parole" en francés. De hecho, el régimen de la cita estandarizado sólo puede operar sobre el mot, pero no sobre la parole. La palabra (hablada se diría) no es citable. Sólo son citables les mots, las palabras a través de las cuales se transduce la parole, la palabra (hablada se diría). Según lo que venimos sugiriendo en este artículo, al día de hoy el libro de Foucault debiera titularse más bien Les mots et les mots. Si esto resultara acertado, quizás no estuviera de más hacer una tentativa de traducción amorosa del título obteniendo algo de verdad del juego entre faux amis de las lenguas francesa y castellana: Los motes y las cosas, donde "mote" sería el sobrenombre dado a la parole, a la palabra (hablada, se diría). La palabra citable sería un mote de la palabra hablada (se diría). Y lo que intentamos en 
este artículo es dar cita con la palabra perdida tras el "régimen de los motes" llamado "orden del discurso". La lógica del sentido es tal que este circula a través del régimen de motes del que constantemente escapa por más que su red de citas se vuelva más y más densa. El sentido de la palabra es de calibre amoroso y, va de suyo, tampoco puede ser captado por el "discurso amoroso" que desmenuza figuralmente Roland Barthes en su libro homónimo, aunque quizás sí por ese desmuzamiento ${ }^{1}$. Se diría que la noción de "discurso amoroso" es un oxímoron. Si la palabra se encuentra bajo el régimen del discurso queda separada de su sentido invariablemente amoroso. Cuando Platón indicaba desconfiar de los caracteres escritos fijos (Carta VII), quizás estuviera indicando desconfiar de los motes de la palabra, suerte de sobre-nombres para el nombre de las cosas². Según se ha dicho (por escrito) que decía (oralmente) Heráclito: Aquello que hemos tomado no lo traemos; aquello que no hemos tomado lo traemos. Así el sentido: todo lo que el sistema de motes del discurso toma del sentido no lo trae consigo; sólo trae consigo el sentido que no ha logrado tomar ${ }^{3}$.

Cuando el Hombre, el Gran Tomador, fue borrado por el mar ${ }^{4}$, Derecho y Literatura siguieron y siguen su existencia pero sin la tensión que las sostenía. En "La locura, la

\footnotetext{
1 "Se puede llamar a estos retazos de discurso figuras. La palabra no debe entenderse en sentido retórico, sino más bien en sentido gimnástico o coreográfico [...] es, de una manera mucho más viva, el gesto del cuerpo sorprendido en acción..." "Las referencias así dadas no son de autoridad sino de amistad: no invoco garantías, evoco solamente, por una suerte de saludo al pasar, lo que seduce, lo que convence, lo que da por un instante el goce de comprender (¿de ser comprendido?)" (Barthes, 1997, "Cómo está hecho este libro", pp. 13 y 18)
}

${ }^{2} Y$ recordar aquí que en francés "nombre" es "número" abriría todo un flujo de sentido difícil de aquilatar en este escrito.

3 "El relato sobre la muerte de Homero nos ayuda a afrontar la interpretación de uno de los fragmentos más oscuros de Heráclito. En este caso es un sabio quien alude al enigma de que ha sido víctima otro sabio. Dice Heráclito: 'Con respecto al conocimiento de las cosas manifiestas los hombre se ven engañados de modo semejante a como le ocurrió a Homero, que fue más sabio que nadie en Grecia. Efectivamente, le engañaron aquellos jóvenes que habían aplastado piojos cuando le dijeron: 'Lo que hemos visto y cogido, lo dejamos; lo que no hemos visto ni cogido, lo traemos". [...] Adoptando como punto de apoyo el enigma homérico, Heráclito enuncia, a su vez, un enigma sobre el enigma..." (Colli, 1996, "El 'pathos' de lo oculto", pp. 54-5)

4 "En todo caso, una cosa es cierta: el hombre no es el problema más antiguo ni el más constante que se haya planeado el saber humano (...) El hombre es una invención cuya fecha reciente muestra con toda facilidad la arqueología de nuestro pensamiento. Y quizá también su próximo fin. Si esas disposiciones desaparecieran tal como aparecieron, si, por cualquier acontecimiento cuya posibilidad podemos cuando mucho presentir, pero cuya forma y promesa no conocemos por ahora, oscilaran, como lo hizo, a fines del siglo XVIII, el suelo del pensamiento clásico, entonces podría apostarse a que el hombre se borraría, como en los límites del mar un rostro de arena". (Foucault, 1993, p. 375) 
ausencia de obra", texto de 1966, Foucault ya vislumbraba un futuro en el que no tendría sentido la Locura que tanto atemorizara a la Razón del Hombre. La nueva subjetivación post-Mickey habrá de estar fármaco-estabilizada y, por consiguiente, tanto Derecho como Literatura habrán quedado tendencialmente desbancadas del centro de la escena del procesamiento dramático (así como alguna vez la Filosofía teológica fuera desbancada por la Óptica de la escena del procesamiento dramático del color).

La más reciente adicción es la adicción al fármaco-diagnóstico. Este comienza desde la infancia. Una suerte de escuela bioquímica que acompaña al proceso de escolarización estatal. El moderno "aprender a escribir" parece haber cedido su lugar a un "aprender a medicarse". En ese marco, la Literatura sufre una transformación análoga a la que alguna vez sufrió la Filosofía. Se diseca, se autoconsuma. Quizás el gesto de acompañamiento que merece y solicita toda autoconsumación, en este caso esté encarnado por la obra de Roberto Bolaño: toda una despedida literaria. Todo un policial literario. Si alguna vez la Literatura supo tomar consistencia de forma o plataforma expresiva partiendo del excedente policial del folletín periodístico, su gesto último es el de tratarse a sí misma como un avatar policial: Escribir es el verdadero policía, y la escritura es su caso.

El drama, mientras tanto, la fuerza dramática del existir, va tomando consistencia a través de nuevas plataformas. Tal como lo anticipara Deleuze, dos años después de "La locura, la ausencia de obra" de Foucault, en Lógica del sentido, el formato base de la nueva literatura es la serie (así como el de la nueva música es el track, no más la canción). No la producción en serie. Más bien la producción de series. Señala Deleuze (1994) en el capítulo "Sobre la serialización":

La paradoja de la que derivan todas las demás es la de la regresión indefinida. Ahora bien, la regresión tiene necesariamente una forma serial: cada nombre designador tiene un sentido que debe ser designado por otro nombre: $\mathrm{n}_{1}-\mathrm{n}_{2}-\mathrm{n}_{3}-\mathrm{n}_{4} \ldots$. (Deleuze, 1994, p. 57)

De allí que producir series sea, de entrada, producir paradojas y, a su vez, trasladar el punto paradójico de toda serie por la serie sucesiva de sus "nombres designadores". Así, en una maxi-serie como Friends, el punto paradójico de la serie pasaba cada vez por el Bar-Sofá ${ }^{5}$ en el que se encontraban a repasar la imposible repetición del drama de la

${ }^{5}$ El nombre del bar era "Central Perk". El desplazamiento de la "a" de Park a la "e" de la cafetera percolator invita a seguir, en plan divertimento aunque sea, una pista filo-derrideana en el asunto, combinando su célebre presentación "La Differànce" con el artículo "La hostilidad absoluta" aparecido en su libro Políticas de la amistad. 
amistad. Por eso a los actores de (una) serie les resulta tan difícil separarse, salirse de esa serie, quedar fuera de ella. Una serie es como un laberinto unidimensional. Inspirados en ese cuento de Leo Masliah, se puede imaginar que, una vez afuera de la serie, el actor dice al "serie-vidente": "Yo no lo ví salir". Y este le responde: "Yo a Usted tampoco".

El Derecho, mientras tanto, va mutando sus maneras hacia una gestión de justicia que administra los ilegalismos con variantes lógicas al castigo/pena. Y es que la sanción puede ser también un premio o una postergación. O un avance. Como en los videogames, cada pantalla lograda permite acceder a otra pantalla más. De allí la inflación posgradual a nivel de formación universitaria. ¿Qué hay más allá del posdoctorado? ¿Cómo se escribe más allá de esa instancia? Evitar la escritura en serie de papers seriales parece equivaler al fin de la escritura y del policial, que es serial desde el principio. La cuestión parece percutir sobre la chance de aceptación de la paradoja, o del punto dramático paradójico. Pero esa es una cuestión que no se investiga; más bien es condición decisiva del modo de expresión de la Investigación del Pensamiento que, al igual que todo Derecho, ha de asumirse como necesaria: preferimos una investigación y un derecho formales y arbitrarios antes que su ausencia.

\section{ENTRE CÁRCEL Y LITERATURA: EL CAMINO DE LA PROSA DEL PENSAMIENTO}

Junto con el Hombre habrán de ir cayendo todos los "lugares de encierro" que había ido detectando lentamente Foucault. El último en caer es la familia, cuya administración policial habrá sido, según rastrea salvajemente el propio Foucault, el origen de toda Polizeiwissenschaft, de toda ciencia de las políticas públicas, de todo conocimiento orientado a la utilidad entendida como acto de gobierno de las conductas vitales.

Ahora bien, como hiciera notar Miguel Morey ya en el año 2005, persiste, eso sí, la cárcel $^{6}$. Y es que, como señala Foucault en unas conferencias en Río de Janeiro (La verdad y las formas jurídicas) del año 1973, la cárcel no es un lugar de encierro. La cárcel es un símbolo de los lugares de encierro. La clave de esos lugares es la normalización. La cárcel

6 "He aquí que las prisiones parecen resistir ahí donde estaban, indiferentes a cualquier cambio, eternamente iguales en lo fundamental a lo que fueron en el siglo XIX. Los últimos avatares políticos, si algo han hecho, ha sido endurecer sus arcaísmos disciplinarios, en un reforzamiento que, legitimado por la amenaza terrorista, no deja de afectar a la sociedad en su totalidad. Aquí los sueños penitenciarios alternativos de la sociedad de control (químicos, electrónicos...) parecen haber encontrado su límite específico, tal vez el punto más ciego del sistema." (Morey, "El porvenir de las instituciones totales. Sociedades de control", La Vanguardia, 30 de noviembre de 2005) 
no normaliza, simplemente recibe los excedentes de la normalización. Por eso la maestra primaria puedo ser llamada la "segunda mamá", y la escuela una "segunda familia". Es en esas dos instituciones donde se jugaba principalmente el juego de la normalización prodigado por las Ciencias del Hombre o Ciencias Humanas.

Elíptica o tal vez entimemáticamente, podría establecerse que: a menos Literatura más Cárcel. El interés de Foucault tanto por los presidios como por la literatura parece apuntar en este sentido. Se diría que en Les mots et les choses, Foucault plasmó una suerte de Novela de la Palabra (parole): las aventuras de la palabra (parole) a través de las palabras (les mots) y las cosas (les choses). Perdida la palabra (parole), el orden del discurso equivale al orden de las cosas. Dicho de otro modo, el orden de las cosas y de la palabra (parole) devenida en motes (mots) es un orden discursivo. Hete ahí las condiciones para el nacimiento de las Ciencias Humanas ${ }^{7}$ y, a la vez, de la Cárcel y la Literatura. Todo lo que no se pueda procesar discursiva y normativa y normalizadoramente implicará un excedente tanto de mots como de choses. El primer excedente habrá de ser típicamente abordado y no-del-todo-procesado por la Literatura, capaz por instantes de acceder a la palabra (parole), al sentido sobreviviente por entre los motes. El segundo excedente habrá de ser típicamente abordado y no-del-todo-procesado por la Cárcel. Cabría decir que Literatura y Cárcel son los dos extremos de la Polizeiwissenschaft, del modo de conocimiento discursivo basado en la consecución de utilidades esto es, de políticas públicas. Es por ello que la Literatura es esencialmente policial y la Cárcel proclivemente literaria: en la Cárcel se encuentran los seres (cosas o cuerpos) reacios a la discursividad que ya fueron procesados por la Administración de Justicia ${ }^{8}$. Ciertamente lo ideal sería plantear a la Cárcel como una instancia de reinserción en la red discursiva (re-socialización). Sin embargo la Cárcel actúa como símbolo de encierro y, como tal, de ella sólo puede escaparse, literariamente. No otra cosa es la Cárcel del Lenguaje, literalmente. A este nivel no resiste metáfora alguna:

"Tengo diecisiete años, me llamo Juan García Madero, estoy en el primer semestre de la carrera de Derecho. Yo no quería estudiar Derecho sino Letras, pero mi tío insistió y al final acabé transigiendo. Soy huérfano. Seré abogado." (Bolaño, Roberto, al comienzo de Los detectives salvajes)

\footnotetext{
${ }^{7}$ Se recordará que el subtítulo de Las palabras y las cosas es Arqueología de las Ciencias Humanas.

${ }^{8}$ Aunque no siempre ser reacio a la discursividad implique ser tambén reacio a la amorosidad y, a su vez, no elimine la chance de una animadversión más profunda que la discursiva.
} 


\section{DE LA SOCIEDAD EN SERIE}

Ahora bien, cabría esperar que los nuevos modos seriales de procesamiento del drama (basados a su vez en la experiencia del asesino serial) alcancen finalmente a la Cárcel en la medida en que, por ejemplo, todo preso o convicto quedara habilitado para tener acceso a Internet. En ese punto lo que Paul Beatriz Preciado llama "fármaco-poder" habría alcanzado también al símbolo del encierro, quedando así el mundo transformado en un gran espacio amniótico desimbolizado, un espacio post-paródico, post-literario, ya casi sin humor alguno, más allá de toda libertad o pena. Aunque también cabría anticipar que, justamente por esto, la Cárcel será protegida como nunca antes, para evitar la catástrofe inherente a la concreción de toda paradoja, en este caso según el loop lógico que alguna vez plantearan Bioy Casares y Borges con su detective H. Bustos Domecq: este resolvía casos policiales desde la celda en la que estaba encarcelado.

Como sea, cabe constatar que Literatura y Derecho no agotaban toda la potencia del Logos, ni mucho menos. Ninguna plataforma puede, por ley de la expresión de Giorgio Colli, hacerlo. El espectro lóguico supo expresarse, antiguamente, según plataformas épicas y líricas y poéticas y musicales y danzantes... Por entre todas las mutaciones que llevaron al Logos a las formas dominantes Derecho y Literatura, Pascal Quignard supo reconocer un modo expresivo que llamó "retórica especulativa". Esta parece desenvolverse desde época romana hasta nuestros días alimentando diversas formaciones más o menos discursivas, proto-discursivas o declaradamente del lado del orden del discurso. Al día de hoy, quizás sea Miguel Morey quien haya tomado el guante, el envite de Quignard. Más allá de la prosa académica, Morey explora una voz lógica que no sea reductible a voz literaria: ni filósofo, ni escritor. Con suerte un filósofo-artista, un filólogo del porvenir. De mínima un profe, un funcionario académico con conciencia de clase (profesoral). Por lo menos una voz reconocible. Un artista de la palabra escrita. Un cantor en prosa. Un gesto enunciador, un posicionamiento de la voz escrita. Una singular efectuación del oído. Quizás por allí viaje una alternativa a Netflix y a la Cárcel, un modo de heredar los principios de la Literatura y no su fortuna acumulada: el camino de la prosa del pensamiento.

\section{ESTILO Y ESTELA DE LA ESCRITURA}

“... la principal enseñanza de la literatura era la valentía, una valentía rara, 
como un pozo de piedra en medio de un paisaje lacustre, una valentía semejante a un torbellino y a un espejo." (Bolaño, Los sinsabores del verdadero policía, pt. 25)

No hay discurso puro ni discurso impuro. Acabar con el discurso puro es acabar con todo discurso. Pero tampoco parece posible generar una prosa totalmente impura, sin resabios de purezas discursivo-académicas. Cada quien irá encontrando a los suyos. O tal vez se trate de irlos inventando, poetizando. De no quedarse con lo ya conocido. Tal vez se trate de darle una chance a la persuasión que insiste y persiste aún en pleno discurso científico archi-validado: ¿qué puede oírse en una noción como genoma? ¿De dónde procede ese influjo jurídico-lingüístico en la noción de código genético? Ciertamente se trata de resolver un enigma, pero queda siempre la cuestión de determinar cuál de todos los enigmas allí presentes es el que necesitamos resolver. Hay quien se dedica a descifrar el código genético. Hay quien se dedica a descifrar la cifra misma expresada en "código genético"9. No por nada el símbolo del ADN es, como diría Aby Warburg, la imagen superviviente del caduceo hermético con sus dos serpientes enroscadas que, a su vez, dicho sea de paso, viaja junto a la cruz en todas las ambulancias de Occidente, y puede encuentrarse a la entrada la Bolsa de Comercio.

Escribir a la luz del día. Con ritmo geológico. Tratando de acallar al "ratón Disney" que insiste en dictarnos su consabida copla, ahora remixada: el viejo sujeto "yo" transformado en circunstancial "para mí". Conjurar al yo y a ese yo-sampler que viaja en cada "para mí". Que ya no tengamos opiniones ni pareceres ni acuerdos ni desacuerdos. Escribir por el medio, en diagonal, oblicuamente. Escribir dejando una estela difícil de seguir, pero que percuta en la sensación de que "por aquí ha pasado algo". Pero entonces: ¿qué ha pasado? Esa es la única cuestión importante: "se ha sentido un obstáculo". Sin enigma no hay gesto. Sin gesto no hay - - - aquello que necesariamente se sustituye con la seguridad ciega que no deja de atemorizarnos por las noches.

\section{ADENDA: LA LITERATURA, LOS DIOSES Y LATINOAMÉRICA}

“¿Y dónde está el maricón de Apolo? Apolo está enfermo, grave." (Bolaño, "Literatura + enfermedad = enfermedad")

\footnotetext{
9 Un gesto en ese sentido es llevado adelante desde 2015 por la investigación del cientista social Pablo Rodríguez en el Laboratorio de Fisiología de Proteínas dirigido por Diego Ferreiro e Ignacio Sánchez en la Facultad de Ciencias Exactas y Naturales de la Universidad de Buenos Aires.
} 
En La literatura y los dioses, el libro que recoge las conferencias que dictara en la Universidad de Oxford en el año 2000, Roberto Calasso (2002) indica una época absoluta de la literatura. Esa época, iniciada en 1799, habrá finalizado en 1923 con la muerte de Rainer María Rilke. Más allá de ese punto quizás sólo cuente Franz Kafka. Pero sabemos que en Latinoamérica ha crecido una literatura absoluta otra, de la cual quizás sea Guillermo Hudson su precursor. Ciertamente Hudson escribió en inglés, pero no por ello Ezequiel Martínez Estrada dejó de considerarlo un principal escritor argentino y latinoamericano. Lo que aquí cabría proponer es que la literatura absoluta latinoamericana nació con Hudson y terminó con Roberto Bolaño, hace tan poco aún, pero ya hace tanto. Al respecto, no deja de resultar significativo que la casa editorial italiana Adelphi, dirigida justamente por Roberto Calasso, cuente entre sus no muchos escritores latinoamericanos publicados, tanto a Guillermo Hudson como a Roberto Bolaño. Mientras tanto, mientras redescubrimos la fuerza literaria de tantos y tantas escritores como quedaron "bloqueados" o "tapados" por el europeo "Boom latinoamericano", corresponde ir rumiando este enigmático comienzo de Roberto Calasso (2002) a sus mencionadas conferencias, aunque más no sea por conjurar el final de aquello que por tierras latinoamericanas quizás no está terminado del todo:

Los dioses son huéspedes huidizos de la literatura. La atraviesan con la estela de sus nombres. Pero, con frecuencia, también la abandonan. Cada vez que el escritor apunta una palabra debe reconquistarlos. La mercurialidad, anuncio de los dioses, es también la señal de su carácter evanescente. Las cosas fueron distintas mientras existió una liturgia. Aquel engarce de gestos y palabras, aquel uso excluyente de ciertos materiales: todo eso placía a los dioses, mientras los hombres quisieron dirigirse a ellos. Después sólo quedaron, como banderines ondeantes en un campamento abandonado, aquellas historias de los dioses que era el sobrentendido de cada gesto. Desarraigados de su suelo y expuestos a la cruda luz de la vibración de la palabra, podían llegar a parecer impúdicos y vanos. Todo acabó en historia de la literatura.

\section{GONZALO S. AGUIRRE}

Doctor en Filosofía (Universidad de Barcelona), Profesor adjunto e investigador de la Facultad de Derecho, Universidad de Buenos Aires. Miembro del Centro de Estudios en Filosofía de la Cultura de la Universidad de Comahue, Argentina. 


\section{REFERENCIAS}

AGUIRRE, Gonzalo. La literatura y las formas jurídicas: la práctica del derecho como drama literario. Revista digital Barda, N³, Neuquén, Centro de Estudios de Filosofía de la Cultura, Universidad Nacional del Comahue, octubre 2016, pp. 57-67.

AGUIRRE, Gonzalo. ¿Qué lengua ha quedado? Foucault y la literatura. Historia de una oquedad.Revista digitalBardaN ${ }^{\circ} 2$, Neuquén, Centro de Estudios de Filosofía de la Cultura, Universidad Nacional del Comahue, Marzo 2016, pp. 35-50, ISSN 2469-1135 (http://www.cefc.org.ar/revista/)

AGUIRRE, Gonzalo y KESSEL, Christian (comp.). Juicio, proceso y drama. Ensayos sobre filosofia y estética del Derecho. Buenos Aires: Aldina, 2017.

BARTHES, Roland. Fragmentos de un discurso amoroso. Madrid: Siglo XXI, 1997.

BLANCHOT, Maurice. El espacio literario. Barcelona: Paidós, 1992.

BOLAÑO, Roberto. Los detectives salvajes. Barcelona: Anagrama, 2007.

BOLAÑO, Roberto. Los sinsabores del verdadero policía. Barcelona: Anagrama, 2012.

BOLAÑO, Roberto. El gaucho insufrible. Barcelona: Anagrama, 2013.

CALASSO, Roberto. La literatura y los dioses. Barcelona: Anagrama, 2002.

COLLI, Giorgio. Filosofía de la expresión. Madrid: Siruela, 1996.

COLLI, Giorgio. El nacimiento de la filosofía. Barcelona: Tusquets, 1996.

DELEUZE, Gilles. Lógica del sentido. Buenos Aires: Paidós, 1994.

DERRIDA, Jacques. Políticas de la amistad. Madrid: Trotta,

FERREIRO, Diego; KOMIVES, Elizabeth y WOLYNES, Pete. "Frustration in Biomolecules". $\begin{array}{lllll}\text { Quaterly Reviews of Biophysics, 2014, } & \text { Vol. }\end{array}$ https://www.ncbi.nlm.nih.gov/pubmed/25225856.

FOUCAULT, Michel.. El orden del discurso. Barcelona: Tusquets, 2008.

FOUCAULT, Michel. La verdad y las formas jurídicas. Barcelona: Gedisa, 1999.

FOUCAULT, Michel. Las palabras y las cosas. Una arqueología de las Ciencias Humanas. México: Siglo XXI, 1993.

FOUCAULT, Michel. "La locura, la ausencia de obra". Apéndice en Historia de la locura en la época clásica II. FCE: Buenos Aires, 2009.

FOUCAULT, Michel. ¿Qué es la Ilustración? (1983 y 1984) en ¿Qué es la Ilustración? Madrid: De la Piqueta, 1996.

FOUCAULT, Michel. Seguridad, territorio, población. Buenos Aires: FCE, 2007. 
LAGI, Sara. El pensamiento político de Hans Kelsen (1911-1920). Los orígenes de 'De la esencia y valor de la democracia'. Madrid: Biblioteca Nueva, 2007.

MASLIAH, Leo. La tortuga y otros cuentos. Buenos Aires: De la Flor, 1990.

MARTÍNEZ ESTRADA, Ezequiel. El maravilloso mundo de Guillermo Enrique Hudson. Rosario: Beatriz Viterbo, 2001.

MOREY, Miguel. Escritos sobre Foucault. Madrid: Sexto Piso, 2014.

MOREY, Miguel. Pequeñas doctrinas de la soledad. México: Sexto Piso, 2007.

MOREY, Miguel. "Del pensar como forma de patología superior", prólogo a Lógica del sentido de Gilles Deleuze, 1994.

MOREY, Miguel. "Traducir los 'Pequeños tratados"” (fragmento de la intervención en el "Coloquio Pascal Quignard. L'écriture et saspéculation" celebrado en París del 7al 9 de diciembre de 2017, realizada por Miguel Morey, autor de la edición en español de Pequeños tratados, Vol. I y II, Sexto Piso, 2016). Revista El cuaderno digital. Gijón: Ediciones Trea, 2018. ISSN: 2255-5730. https://elcuadernodigital.com/2018/03/20/en-torno-a-pascalquignard/

PRECIADO, Paul Beatriz, Testo yonqui. Sexo, drogas y biopolítica. Buenos Aires: Paidós, 2017.

QUIGNARD, Pascal. Retórica especulativa. Buenos Aires: Cuenco de Plata, 2006.

QUIGNARD, Pascal. El sexo y el espanto. Barcelona: Minúscula, 2006.

RODRÍGUEZ, Pablo E. “Dogma Periférico. ¿De qué mensaje me están hablando?”. En Química Viva, revista electrónica del Departamento de Química Biológica de la Facultad de Ciencias Exactas y Naturales de la Universidad de Buenos Aires, Instituto de Química Biológica. $\quad$ Vol.14, nro.2, 2015.ISSN: $1666-7948$. http://www.quimicaviva.qb.fcen.uba.ar/v14n2/rodriguez.html.

WARBURG, Aby. El ritual de la serpiente. Madrid: Sexto Piso, 2008.

WEBER, Max. Economía y Sociedad. Madrid: FCE, 2002. 